\title{
EU Trade Regulations and Imports of Hygienic Poultry
}

\section{Mahdi Ghodsi}

The Vienna Institute for International Economic Studies (wiiw), Vienna, Austria

ghodsi@wiiw.ac.at

\section{Robert Stehrer}

The Vienna Institute for International Economic Studies (wiiw), Vienna, Austria

stehrer@wiiw.ac.at

\section{CroEconsur}

Vol. 21

No. 2

December 2019

pp. 117-149

Received: July 26, 2018

Accepted: September 9, 2019

Research Article

doi:10.15179/ces.21.2.4

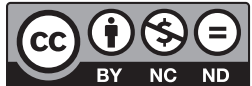

\section{Abstract}

This study sheds light on particular issues of poultry imports to the EU during the 1996-2014 period. First, we analyze the mechanisms of EU market protection through the evolution of tariffs and non-tariff measures (NTMs), both descriptively and econometrically. Second, we estimate bilateral ad valorem equivalents (AVEs) of different types of NTMs imposed on the imports of poultry to the EU. These AVEs hint towards the diverse impact of NTMs on various exporters based on their production compatibilities with EU standards. Third, we analyze the quality impact of NTMs, which are also differentiated by the exporting countries.

Keywords: EU regulations, non-tariff measures, gravity model, ad valorem equivalents, product quality

JEL classification: F13, F14, Q17 


\section{Introduction'}

Within the traditional trade policy frameworks, tariffs have been the main instrument to protect the domestic industries and consumers by raising the tax on the imports of undesired products. Since the General Agreement on Tariffs and Trade (GATT) and World Trade Organization (WTO) have facilitated trade liberalization by lowering tariff rates, especially in advanced economies, non-tariff measures (NTMs) have become more attractive tools to regulate the flows of products to a country. WTO agreements allow member states to impose qualitative regulations, standards, and security and safeguard measures in order to improve safety, human and animal health, environmental quality, and market efficiencies. However, complying with these regulations makes them traderestrictive. Therefore, these measures are sometimes also referred to as non-tariff barriers to trade.

As long as the standards embodied within the NTMs improve the quality of the products so that the consumer health or environmental quality improves, the imposition of these trade policy tools might be accepted by trade partners. However, there are not yet many evident and scientific arguments behind their imposition, particularly if quality standards and preferences differ.

For instance, the EU legislations within sanitary and phytosanitary (SPS) measures against genetically modified organisms (GMOs) and hormones in meats restrict the imports of biotech agricultural and food products. The introduction of these measures caused dispute settlement cases consulted with the Dispute Settlement Body (DSB) of the WTO, as the imports to the EU were restricted. In the hormones case, the final decisions of arbitrators determined CAD 11.3 million and USD 116.8 million as the level of nullification suffered by Canada and the USA, respectively. In the biotech case, although there was a mutually agreed solution between the EU, Canada, and Argentina, on January 2008, the

1 This paper was produced as part of the project "Productivity, Non-Tariff Measures and Openness" (PRONTO) funded by the European Commission under the 7th Framework Program, Theme SSH.2013.4.3-3 "Untapped Potential for Growth and Employment Reducing the Cost of Non-Tariff Measures in Goods, Services and Investment", Grant agreement No. 613504. 
request for retaliation by the US was approved by the DSB of the WTO. Despite the intention of the EU to protect its society and its final consumers by imposing the quality standards, no scientific evidence has been provided so far justifying the trade restrictiveness of these NTMs.

Similar debates are still ongoing about other regulations in force, regarding what the media has dubbed "chlorinated chicken". This is a restriction on the imports of poultry washed with certain pathogen reduction treatments (PRTs). The ban has existed in the EU market since 1997 with several amendments. In October 2006, the US raised a specific trade concern (STC) against the SPS measures imposed by the EU to the WTO claiming that "although the European Commission had proposed legislation permitting the use of PRTs in January 2006, the ban on imported poultry had not been removed". The EU legislation would suggest that the use of antimicrobial treatments (AMTs) might be abused to compensate for the low hygienic quality of production. If the set of quality standards for poultry in an exporting country such as the US were high enough, they could increase their exports to the EU, eliminating the use of AMTs and PRTs. Finally, in January 2009, the US asked the DSB for consultations with the EU regarding these regulations and some other members reserved their third-party rights, while the panel body has not yet been set up for the case.

Therefore, the arguments pro and con can go beyond an individual country when it comes to standards and regulations. In general, when an exporting country produces at similar production standards as the country imposing the regulations does, the implication of the NTM is not necessarily trade-restrictive. However, there might be certain quality improvements in the countries that are not achieving the same level of standards. With respect to the recent trade negotiations, it is important to see how the two economic partners meet each other's standards. For instance, a study by Dal Bianco, Boatto, Caracciolo, and Santeramo (2015) indicates that SPS regulations do not hinder global wine exports. However, different requirements of technical barriers to trade (TBTs) have diverse impeding effects on wine exports. Disdier, Fontagné, and Cadot (2015) provide empirical 
evidence that even the North-South harmonization of standards has had a negative influence on South-South trade. Harmonization of regional standards harms North-South trade while the international standards harmonization could stimulate it. It can be argued that the existing framework of standards between the two partners can identify the contractual terms of the agreements, in which standard-like trade barriers and NTMs could be implemented.

A problem emerges when the domestic legal systems of countries diverge substantially. De Frahan and Vancauteren (2006) provide empirical evidence in a gravity framework that the harmonization of food regulations within the EU has significantly increased intra-EU trade. However, regulations within the EU could essentially differ from those of other countries such as the United States, mainly because the legal systems are different. For instance, in the EU producers are responsible for initially proving that their products do not harm the consumers; only then are they permitted to produce. In contrast, according to international regulations within the WTO agreements, which are closer to the legal framework in the US, production shall not be halted until evidence is provided that the consumer is harmed by the product. These systematic differences determining the trade regulations have resulted in several trade disputes.

Where scientific evidence for trade restrictions is not available or remains disputed, standards and NTMs might lead to economic losses by trade disputes due to differences in the legal systems of the two sides in the conflict. Such disputes could be avoided by mutual recognition of such differences in the legal systems. Some scholars discuss asymmetries of information between the two trade partners when a complete ban is caused by trade regulations that are not in line with the international standards or any scientific evidence (Bown \& Hillman, 2016, 2017).

Due to their delicate health-related issues, food and agricultural products are considered to be the most important products with respect to concerns of consumers in shaping policies of the governments and ultimately trade partnership 
agreements. Otsuki, Wilson, and Sewadeh (2001) focused on the stringency of EU regulations on aflatoxins based on a major health concern of the policymakers within the EU that considerably hampers the food imports from Africa.

Scholars study the different impacts of regulations on the global demand and trade of food products. The findings of Fontagné, Mimouni, and Pasteels (2005) suggest a trade-hampering effect of regulations on only some specific products. Disdier, Fontagné, and Mimouni (2008) find diverse impacts of NTMs on the imports of different countries. SPS measures impose less trade costs on the US exports of corn than distance and tariffs do according to the study by Jayasinghe, Beghin, and Moschini (2010). Winchester et al. (2012) also address the impeding effect of NTMs on agricultural trade by defining the heterogeneity index measuring the diverse regulations between the exporter and the importer. Empirical evidence on the US phytosanitary measures on fresh fruit imports found by Peterson, Grant, Roberts, and Karov (2013) suggests that the negative impact of these measures diminishes as the exporters gain experience in facing these regulations after a while until they completely comply with them. Melo, Engler, Nahuehual, Cofre, and Barrena (2014) show that the stringency of SPS measures and quality-related standards impede the Chilean fruit exports dramatically.

This paper focuses on the implications of NTMs imposed on poultry trade to the EU. Using an empirical framework, the impact of NTMs on imports is differentiated by trade partners and by product categories. As discussed above, the literature is rich in the trade consequences of NTMs but to our knowledge there is a lack in assessing quality impacts. Using a dataset provided by Feenstra and Romalis (2014), the quality and quality-adjusted price of the traded products are differentiated, which can hint towards the quality impact of NTMs based on the existing standards of the exporting countries. Additionally, NTMs notified to the WTO and compiled under the Integrated Trade Intelligence Portal (I-TIP) are used in this analysis. Most importantly, the impact of both TBT and SPS measures imposed by the EU on the quality and price of imports of poultry to the 
$\mathrm{EU}$ is differentiated by the exporting country, which we see as the most important contribution to the existing literature.

The rest of the paper is structured as follows. In the second section, EU poultry imports are analyzed descriptively and the impact of NTMs imposed by the EU on poultry imports is assessed econometrically. Ad valorem equivalents (AVEs) of EU notifications are then presented and analyzed in the third section. Section four analyzes the quality impact of EU measures. Finally, section five concludes.

\section{EU Poultry Imports and Trade Policy}

\subsection{Descriptive Analysis}

According to the European Commission, the poultry sector ${ }^{2}$ in the EU (characterized by an excess export of about 3 percent of the production in 2014) is one of the major producers in the world. Trade in this sector has evolved since 1996. Figure 1 shows that a major part of this development was mainly due to the increase of intra-EU trade. This increasing trend of trade among the EU member states was mostly due to the accession of new member states (NMSs) such as Poland with the highest production of about 13 percent of total EU poultry production ${ }^{3}$ and second highest intra-EU export of 15 percent (after the Netherlands with 26 percent of intra-EU export) in 2014. However, extra-EU trade stayed rather low and lost its importance over years. While extra-EU trade accounted for 18 percent of total EU imports of poultry products, it gradually decreased to 12 percent after the accession of NMSs in 2004 and to 6.6 percent in 2014. This indicates a preference for consumption of EU-produced products, which might result from different standards and trade policy measures within the EU market.

2 Here the trade data on poultry refer to sector 0114 of SITC Rev. 2, which are all corresponding products within sector 0207 in HS Rev. 1996 excluding fresh or chilled edible fatty livers of ducks or geese coded in 020734.

3 More details can be found at: http://ec.europa.eu/agriculture/poultry/index_en.htm 
Figure 1: EU Poultry Imports - Intra vs. Extra

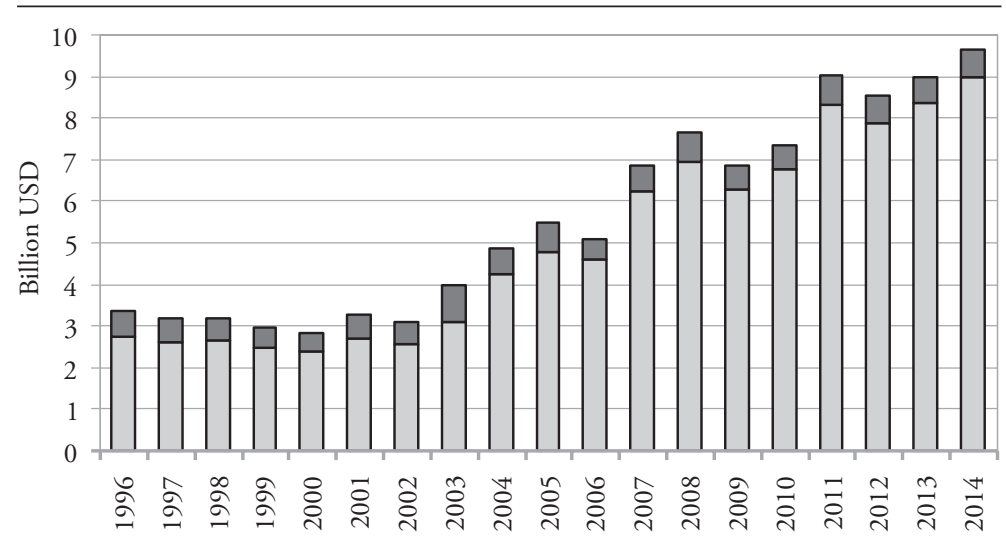

$\square$ Intra-EU Imports $\quad \square$ Extra-EU Imports

Source: UN Comtrade.

Figure 2: Partners' Share in Extra-EU Poultry Imports

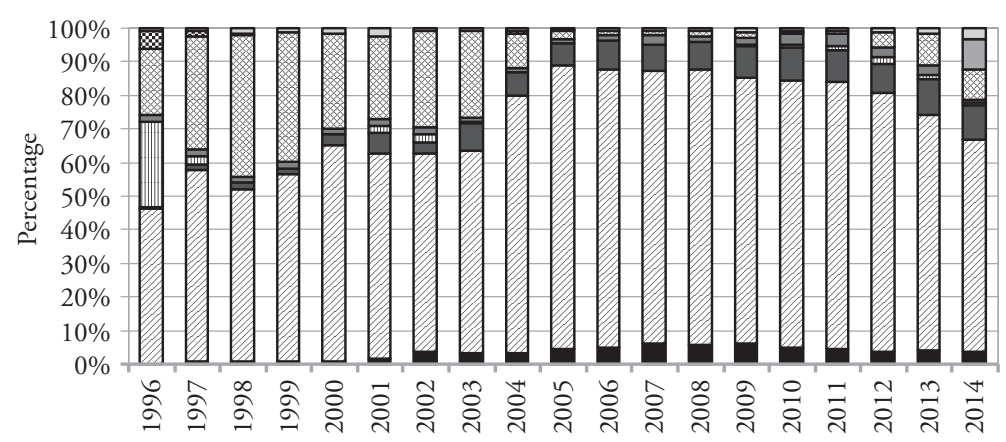

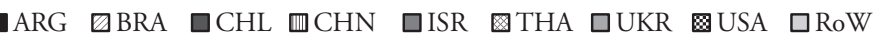

Source: UN Comtrade. 
Figure 2 shows some of the major extra-EU suppliers of poultry products. Among extra-EU exporters, Brazil is the major supplier of poultry; its share reached as much as 84.5 percent of extra-EU imports in 2005. Until 2002, Thailand had been the second major exporter of poultry to the EU with 28 percent of extraEU imports. However, after 2003 it was replaced by Chile with over 10 percent of extra-EU imports. Argentina is another South American large supplier of poultry to the EU with an average share of 4.3 percent since the turn of the new millennium. In 2014, Ukraine became another major exporter of poultry to the EU, covering around 9 percent of extra-EU imports, after the EU had granted unilateral trade preferences to Ukraine following the "Maidan revolution". The United States have accounted for less than 1 percent of extra-EU poultry imports since 1997.

The decreasing share of extra-EU imports of poultry coincides with an increasing number of qualitative NTMs. Figure 3 shows that the number of EU regulations within SPS measures and TBTs notified to the WTO has increased since 1996. Most of these SPS measures and all TBTs are imposed against all countries in the world. Regulations imposed by the EU range from emergency SPS measures for the protection of human health against avian influenza in Chile to regular unilateral SPS measures regarding salmonella in fresh poultry meat, and to labelling and consumer information measures within TBTs. There are a few STCs that are raised against the imposition of other SPS measures and TBTs that are not directly notified to the WTO. However, among the TBTs and SPS measures, there are also some STCs that are raised against the directly notified measures by the EU to the WTO. In 2006, the USA raised an STC against an EU regulation on PRT usage that had been in force since 1997. This regulation also coincides with a sudden fall in the imports from the US as depicted in Figure 2. There are also a few special safeguards (SSGs) during the period that were mainly pricebased measures to control import surges due to price falls. 
Figure 3: NTMs on Poultry Maintained by the EU

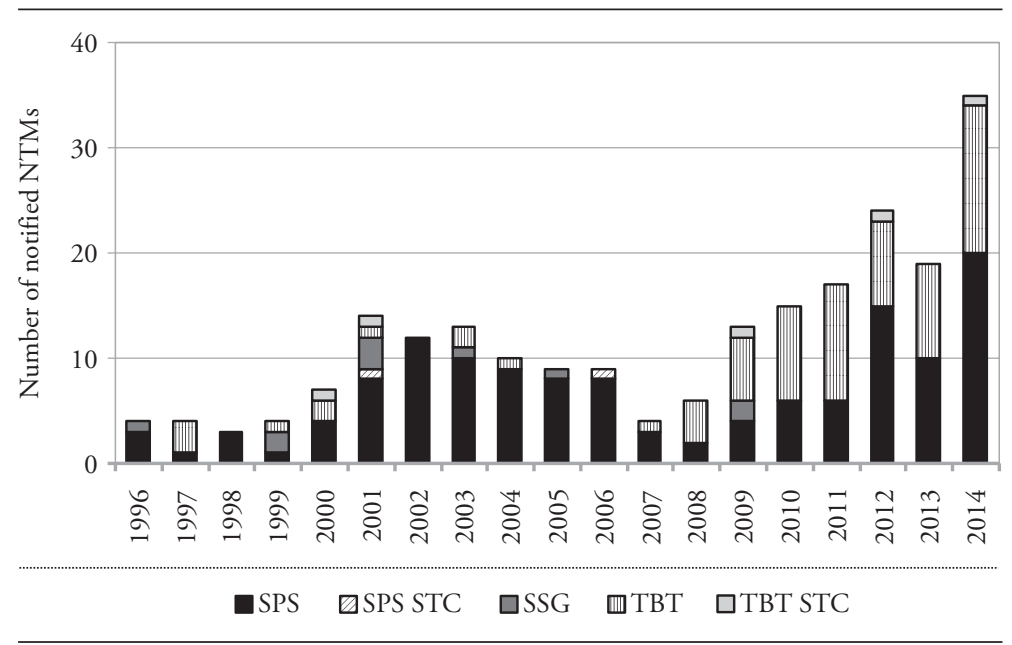

Source: Ghodsi, Grübler, Reiter, and Stehrer (2016).

Figure 4: EU Effective Trade Policy on Poultry Imports

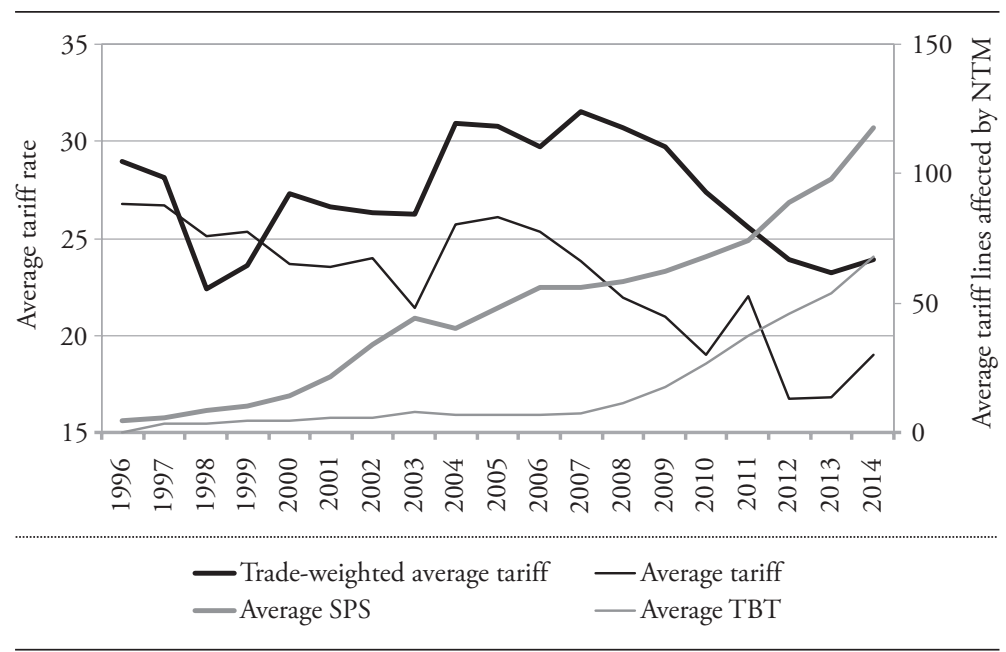

Source: Ghodsi et al. (2016). 
It should be noted that some NTMs focus on more than one product and some are also related to specific substances that are used in the production of other intermediate goods used in the production of poultry. This results in a larger effectiveness of a given NTM. Some of the (non)discriminatory NTMs are also effective against the imports from several other countries, which affects a larger number of bilateral trade flows. Therefore, instead of considering the number of NTMs notified to the WTO, one can get a more precise picture of these policy measures by observing their effective coverage. The average number of NTMs affecting detailed bilateral trade flows (here the level of detail is the 6-digit HS product classification) is seen as a good proxy measuring the effective coverage.

The effective coverage of the NTMs is depicted in Figure 4. Again, it is evident that the average number of NTMs affecting bilateral 6-digit tariff lines is increasing over time. Since SPS measures are typically regulations on food safety, standards, and human health, the coverage of SPS measures on poultry imports are more effective than that of TBTs. Another interesting point concerns the average tariff in the sector that had a peak of 26 percent in 2005 and gradually decreased to its lowest level of 17 percent in 2013. Considering the trade-weighted average (TWA), tariffs show a slightly different picture. In fact, the highest TWA imposed effectively by the EU was above 31 percent in 2007, coinciding with the financial crisis. This shows that product lines with higher trade values were affected by higher tariff rates. Moreover, the overall picture shows that while tariffs have been reduced over the years by WTO concession commitments and by EU customs unions, effective imposed NTMs emerged. Together with the decreasing share of extra-EU trade, it can be argued that NTM proliferation was more effective than tariff reduction as a restrictive trade policy measure. In the following subsection, we test this econometrically. 


\subsection{Gravity Framework}

Since we are interested in analyzing the impact of the trade policy measures implemented by the EU on bilateral import flows of poultry to the EU, we need to apply a structural gravity framework, which is a common methodology in the literature. Bilateral trade flows were studied first in the gravity framework by Tinbergen (1962). This seminal gravity framework econometrically assesses how trade volumes are determined as a function of economic size of the two trading partners (e.g., GDP) and the geographical distance between them. This framework has been extended and widely developed in the literature since then. Using a theoretical model with constant elasticity of substitution, Anderson (1979) conceptualized gravity in a theoretical framework. Later, in an imperfect competition framework, Eaton and Kortum (2002) and Anderson and van Wincoop (2003) developed the structural gravity model with multilateral resistance terms. Many other economic factors and trade policy measures affecting trade flows, and their impact on welfare, are extensively studied using the structural gravity model (see, e.g., Arkolakis, Costinot, \& Rodríguez-Clare, 2012; Yotov, Piermartini, Monteiro, \& Larch, 2016; Dhingra et al., 2017, for recent contributions).

The analysis in this paper builds on this recent literature with respect to the structural gravity framework (see Head \& Mayer, 2014) to study how the trade policy measures implemented by the European Union on poultry products affect the patterns of imports and the related quality of products. Therefore, a formal structural gravity framework is used to study the impact of NTMs on the imports of poultry to the 28 member states of the EU from all over the world. More concretely, the following gravity equation is estimated:

$$
\begin{aligned}
& \ln \left(m_{i j h t+1}\right)=\alpha_{0}+\alpha_{T} \ln \left(1+T_{i j h t}\right)+\sum_{n=1}^{N} \ln \left(1+N T M_{n i j h t}\right)+\beta_{1} G_{i j t}+\beta_{2} E U_{i t}+ \\
& +\omega_{i j h}+\omega_{i t}+\omega_{j t}+\mu_{i j h t}, \\
& n \in\{T B T, S P S, T B T \text { STC, SPS STC, SSG, ADP }\},
\end{aligned}
$$


where $\ln \left(m_{i j h t+1}\right)$ is the natural logarithm of the respective trade indicator of the HS 6 -digit product $h$ imported to country $i$ from country $j$ at time $t+1$. We use trade value (in USD), trade quantity, and trade price (unit value in USD) as three indicators of the dependent variable in separate estimations. Trade data are collected from UN Comtrade. $T_{i j h t}$ is the effective tariff rate imposed on the traded product at time $t$. Tariff is compiled as AVEs of tariffs estimated by the UNCTAD method. Priority of tariff information is firstly effectively applied rates; where they are not available, preferential tariffs are used; and when none of them exists, the most-favored nation (MFN) tariffs are used. $N T M_{n i j h t}$ represents the number of NTMs of type $n$ being in force or initiated at time $t$ by the EU against partner $j . G_{i j t}$ is a vector of gravity covariates common in the literature capturing country-pair characteristics and consists of classical gravity variables and factor endowments. It includes traditional market potential of trade partners that is the natural logarithm of the sum of both countries' expenditure-side real GDP $\left(g_{i j t}\right)$. Additionally, we use the output-side real GDP per capita for the economic development of a country and use it in the indicator used by Baltagi, Egger, and Pfaffermayr (2003) as follows:

$y_{i j t}=\left(\frac{G D P p c_{i t}^{2}}{\left(G D P p c_{i t}+G D P p c_{j t}\right)^{2}}+\frac{G D P p c_{j t}^{2}}{\left(G D P p c_{i t}+G D P p c_{j t}\right)^{2}}\right)-\frac{1}{2}, y_{i j t} \in(0,0.5)$.

In addition, $G_{i j t}$ includes distance between the trading partners in three relative factor endowments: labor force $L$, capital stock $K$, and agricultural land area $A$ as follows:

$f_{k i j t}=\ln \left(\frac{F_{k j t}}{\left(G D P_{j t}\right)}\right)-\ln \left(\frac{F_{k i t}}{\left(G D P_{i t}\right)}\right), F_{k} \in\{L, K, A\}$.

Data for the aforementioned gravity variables are gathered from the Penn World Tables (Feenstra, Inklaar, \& Timmer, 2015). Further gravity variables that enter our regressions are the exchange rate of the partner country in the importer's currency $\left(\mathrm{Xr}_{i j t}\right)$, a dummy variable for preferential trade agreement (PTA) between the two partners, and a dummy indicating intra-EU trade (i.e., both partners are 
EU members at time $t$ ). Since all EU-28 members are included as importers in the sample, a dummy variable indicating the EU membership of the importer is also included, denoted by $E U_{i t}$. These variables are all in current US dollars as collected from international sources.

Furthermore, some fixed effects are included to capture the multilateral resistances. In fact, in the first specification, only country-pair-product fixed effects $\left(\omega_{i j h}\right)$ and time fixed effect $\left(\omega_{t}\right)$ are added in the panel fixed effect estimation. In the second specification, importer-time $\left(\omega_{i t}\right)$ and exporter-time $\left(\omega_{i j}\right)$ effects are added instead of time-fixed effects. While those two specifications are estimated by normal OLS, in a third specification, Poisson estimation controlling for country-pair-product and time fixed effects is used to additionally control for zero trade flows.

In an important contribution, Silva and Tenreyro (2006) argue that in a log-linearized model, normal OLS would give biased estimators due to heteroscedasticity. For the estimation of the gravity model in particular, they propose Poisson pseudo-maximum-likelihood (PPML). PPML is then extensively applied in the estimation of gravity models that also controls for available zero trade value in the dependent variable, which drops out of the sample after taking the logarithm. Zero bilateral trade flow in a given year could be an indication of large trade costs leading to falling extensive margins to trade (Melitz, 2003; Helpman, Melitz, \& Rubinstein, 2008; Bingzhan, 2011; Larch, Wanner, Yotov, $\&$ Zylkin, 2018). Therefore, dropping those zero trade values from the estimation could cause a sample selection bias ${ }^{4}$. Inclusion of country-time effects in the Poisson estimation could cause non-convergence in the estimation. Because of many missing observations in explanatory variables (such as tariffs), it would not be possible to estimate a full balanced panel via the Poisson regressions. ${ }^{5}$

Further, it is necessary to also control for the possible endogeneity bias. One source of endogeneity bias is related to the omitted variables bias. According to

4 However, when such zero trade flows are country-specific, meaning that a given country-pair has never experienced a non-zero trade over time, the country-pair fixed effects could control for that.

5 Since zero price could not be correctly interpreted, Poisson estimate is not presented for unit values. However, the estimation results are available upon request. 
the theoretical foundations of structural gravity, this bias is controlled by using the necessary fixed effects (Anderson \& van Wincoop, 2003; Baldwin \& Taglioni, 2007; Larch et al., 2018). Another source of endogeneity is related to the reverse causality bias. In other words, when import flows surge, policymakers might impose protectionist trade policy measures to restrict trade flows. Therefore, the contemporaneous trade flow (dependent variable) might affect the imposition of new NTMs (explanatory variables). And as the dependent variable is by definition dependent on the error term, the explanatory variable would correlate with the contemporaneous error causing the endogeneity bias. In order to reduce the endogeneity bias of NTMs due to the simultaneity and reverse causality, gravity literature uses the lags of NTMs (Bao \& Qiu, 2012; Imbruno, 2016). Therefore, in this paper all explanatory variables are also lagged.

Table 1 presents the results of the gravity model estimations on the EU-28 poultry imports from all over the world. The first panel to the left shows the OLS results controlling for only bilateral product and time fixed effects (FEs), which is the same as panel FE. The middle panel shows the estimation results controlling for additional country-time effects. The third panel shows the Poisson FE results controlling for the zero trade flows. The sample under estimation excluding zero trade flows has 31,283 bilateral trade flows, while the sample size including all zero and positive trade flows under estimation is 93,910. In all regressions, tariffs affect trade flows negatively. After controlling for country-time effects, which in theory captures the multilateral resistances, SPS measures show to be tradeenhancing. In addition, controlling for the zero trade flows, Poisson regressions suggest that tariff lines affected by SPS measures have higher trade values and quantities. However, these have no statistically significant impact on trade unit values reflecting the product cost or quality.

STCs that are raised by exporters against SPS measures imposed by the EU statistically significantly increase the price of traded products controlling for bilateral-product effects. However, since these measures are country-time observations in the sample, controlling for those country-time effects in the 
second panel hints to an opposite but insignificant impact of these measures on prices.

TBTs imposed on poultry imports statistically significantly reduce trade flows, which is robust in all specifications. In fact, results in the first panel suggest that a 1 percent increase in the number of TBTs imposed on poultry products can substantially decrease the traded quantity and value by about 0.3 percent, which translates to around 30 percent marginal impact of TBTs on trade. Drawing on results from the Poisson estimates, while both quantity and value of trade are reduced by TBTs, it can be argued that the implication of TBTs on the imported poultry to the EU is not quality- but cost-increasing, which leads to lower demand. However, in the middle panel where the changes in preferences of the importing country and the production patterns of the exporter countries are controlled by the FE, the impact of TBTs on import prices is negative. This might further indicate a lower price or quality of products induced by TBTs, where those patterns are captured by the FE showing the trade restrictiveness of these measures on poultry imports.

TBT STCs do not statistically significantly affect the dependent variables except in one specification. As can be interpreted from the first panel, over time, they only increase the price of imports from the partner country raising them to the WTO, but have no significant influence on their trade values.

Table 1: Gravity Estimations on EU Poultry Import

\begin{tabular}{|c|c|c|c|c|c|c|c|c|}
\hline Estimation & \multicolumn{3}{|c|}{ OLS } & \multicolumn{3}{|c|}{ OLS } & \multicolumn{2}{|c|}{ Poisson } \\
\hline Dep. Var. & Value & Quantity & Price & Value & Quantity & Price & Value & Quantity \\
\hline \multirow[t]{2}{*}{$\alpha_{T}$} & $-1.43^{* * *}$ & $-1.34^{* * *}$ & 0.083 & $-1.26^{* *}$ & $-1.53^{* *}$ & -0.27 & -0.23 & $-1.12^{* * *}$ \\
\hline & $(0.34)$ & $(0.36)$ & $(0.10)$ & $(0.60)$ & $(0.63)$ & $(0.17)$ & $(0.44)$ & $(0.42)$ \\
\hline \multirow[t]{2}{*}{$\alpha_{S P S}$} & -0.0019 & 0.015 & 0.017 & $0.43^{*}$ & $0.47^{*}$ & 0.043 & $0.23^{* *}$ & $0.17^{*}$ \\
\hline & $(0.072)$ & $(0.076)$ & $(0.019)$ & $(0.23)$ & $(0.24)$ & $(0.082)$ & $(0.10)$ & $(0.095)$ \\
\hline \multirow[t]{2}{*}{$\alpha_{\text {SPSSTC }}$} & -0.23 & -0.0081 & $0.23^{* * *}$ & -0.43 & -0.50 & -0.073 & $-1.37^{*}$ & $-2.09^{* *}$ \\
\hline & $(0.27)$ & $(0.27)$ & $(0.073)$ & $(0.60)$ & $(0.67)$ & $(0.18)$ & $(0.77)$ & $(0.82)$ \\
\hline \multirow[t]{2}{*}{$\alpha_{T B T}$} & $-0.29^{* * *}$ & $-0.30^{* * *}$ & -0.0035 & -0.34 & $-0.44^{*}$ & $-0.11^{*}$ & $-0.33^{* * *}$ & $-0.38^{* * *}$ \\
\hline & $(0.065)$ & $(0.067)$ & $(0.015)$ & $(0.23)$ & $(0.24)$ & $(0.062)$ & $(0.075)$ & $(0.085)$ \\
\hline$\alpha_{\text {TBTSTC }}$ & -0.066 & 0.13 & $0.20^{* * *}$ & 0.51 & 0.37 & -0.14 & 0.45 & 0.58 \\
\hline
\end{tabular}




\begin{tabular}{|c|c|c|c|c|c|c|c|c|}
\hline & $(0.25)$ & $(0.26)$ & $(0.058)$ & $(0.95)$ & $(0.85)$ & $(0.28)$ & $(0.42)$ & $(0.41)$ \\
\hline \multirow[t]{2}{*}{$\alpha_{S S G}$} & $0.19^{*}$ & 0.12 & $-0.071^{* * *}$ & 0.11 & 0.045 & $-0.061^{*}$ & $-0.35^{* *}$ & -0.27 \\
\hline & $(0.11)$ & $(0.11)$ & $(0.027)$ & $(0.14)$ & $(0.14)$ & $(0.035)$ & $(0.15)$ & $(0.17)$ \\
\hline \multirow[t]{2}{*}{$\alpha_{A D P}$} & & & & & & & $-6.65^{* * *}$ & $-10.0^{* * *}$ \\
\hline & & & & & & & $(1.54)$ & $(1.38)$ \\
\hline \multirow[t]{2}{*}{$g_{i j t}$} & $1.30^{* * *}$ & $1.19^{* * *}$ & -0.10 & $1.53^{*}$ & $1.84^{* *}$ & 0.31 & $1.87^{* * *}$ & $1.46^{* * *}$ \\
\hline & $(0.30)$ & $(0.31)$ & $(0.088)$ & $(0.75)$ & $(0.79)$ & $(0.23)$ & $(0.33)$ & $(0.31)$ \\
\hline \multirow[t]{2}{*}{$y_{i j t}$} & -0.00086 & 0.0061 & $0.0069^{* *}$ & -0.0056 & -0.0031 & 0.0025 & 0.00039 & 0.015 \\
\hline & $(0.0094)$ & $(0.0098)$ & $(0.0029)$ & $(0.010)$ & $(0.011)$ & $(0.0033)$ & $(0.011)$ & $(0.011)$ \\
\hline \multirow[t]{2}{*}{$f_{\text {Lijt }}$} & -0.18 & -0.28 & -0.10 & 27437.6 & -86337.2 & -113774.8 & 0.19 & -0.22 \\
\hline & $(0.24)$ & $(0.26)$ & $(0.072)$ & (.) & $(880486.6)$ & $(1386957.6)$ & $(0.35)$ & $(0.33)$ \\
\hline \multirow[t]{2}{*}{$f_{K i j t}$} & $0.30^{* *}$ & $0.22^{*}$ & $-0.080^{* *}$ & -18961.7 & -27455.5 & -8493.8 & $0.44^{* *}$ & $0.49^{* * *}$ \\
\hline & $(0.12)$ & $(0.12)$ & $(0.035)$ & (.) & $(309060.7)$ & $(489766.1)$ & $(0.17)$ & $(0.17)$ \\
\hline \multirow[t]{2}{*}{$f_{A i j t}$} & 0.13 & 0.24 & 0.12 & -89940.5 & -33786.0 & 56154.5 & 0.54 & 0.54 \\
\hline & $(0.34)$ & $(0.36)$ & $(0.095)$ & (.) & $(469137.2)$ & $(722122.8)$ & $(0.54)$ & $(0.56)$ \\
\hline \multirow[t]{2}{*}{$X r_{i j t}$} & -0.0043 & $-0.0078^{*}$ & $-0.0035^{*}$ & -0.0015 & -0.0057 & $-0.0041^{* *}$ & -0.0035 & -0.0071 \\
\hline & $(0.0042)$ & $(0.0045)$ & $(0.0020)$ & $(0.0056)$ & $(0.0064)$ & $(0.0020)$ & $(0.0051)$ & $(0.0045)$ \\
\hline \multirow[t]{2}{*}{ PTA } & $0.41^{* *}$ & $0.46^{* *}$ & 0.048 & 0.11 & 0.086 & -0.027 & $1.28^{* * *}$ & $1.24^{* * *}$ \\
\hline & $(0.20)$ & $(0.20)$ & $(0.055)$ & $(0.49)$ & $(0.51)$ & $(0.12)$ & $(0.22)$ & $(0.18)$ \\
\hline \multirow[t]{2}{*}{ Intra-EU } & -0.27 & -0.12 & $0.15^{* * *}$ & -395.2 & 3398.9 & 3794.1 & $0.55^{*}$ & 0.33 \\
\hline & $(0.24)$ & $(0.25)$ & $(0.058)$ & (.) & $(35254.1)$ & $(55707.0)$ & $(0.32)$ & $(0.28)$ \\
\hline \multirow[t]{2}{*}{$E U_{i t}$} & 0.27 & 0.017 & $-0.25^{* * *}$ & 0.42 & 0.40 & -0.011 & -0.18 & $-0.50^{* *}$ \\
\hline & $(0.20)$ & $(0.21)$ & $(0.050)$ & $(0.67)$ & $(0.70)$ & $(0.21)$ & $(0.23)$ & $(0.20)$ \\
\hline \multirow[t]{2}{*}{ Constant } & -6.39 & -5.75 & 0.64 & -45756.2 & -92101.9 & -46345.7 & & \\
\hline & $(4.16)$ & $(4.30)$ & $(1.22)$ & (.) & $(1016551.7)$ & $(1611701.7)$ & & \\
\hline$\omega_{i j h}$ & Yes & Yes & Yes & Yes & Yes & Yes & Yes & Yes \\
\hline$\omega_{t}$ & Yes & Yes & Yes & No & No & No & Yes & Yes \\
\hline$\omega_{i t}$ & No & No & No & Yes & Yes & Yes & No & No \\
\hline$\omega_{j t}$ & No & No & No & Yes & Yes & Yes & No & No \\
\hline $\mathrm{N}$ & 31283 & 31283 & 31283 & 31283 & 31283 & 31283 & 93910 & 93910 \\
\hline R-sq & 0.769 & 0.776 & 0.708 & 0.795 & 0.800 & 0.731 & & \\
\hline Adj. R-sq & 0.735 & 0.743 & 0.665 & 0.754 & 0.761 & 0.680 & & \\
\hline
\end{tabular}

Notes: Robust standard errors in parentheses (clustered by country-pair-products).

${ }^{*} \mathrm{p}<0.1,{ }^{* *} \mathrm{p}<0.05,{ }^{* * *} \mathrm{p}<0.01$.

Source: Authors' estimations.

The interpretation of the results of other explanatory variables is rather straightforward. ${ }^{6}$ Market potential $\left(g_{i j t}\right)$ increases trade flows, while differences

6 Antidumping (ADP) measures in the sample do not relate to many positive trade flows, but they are mainly reflected in the Poisson estimations including zero trade flows over time in the panel. Thus, they are very traderestrictive with statistically significant negative coefficients leading to zero trade flows. 
in the economic development $\left(y_{i j t}\right)$ increase the trade unit values. Difference in physical capital between the trade partners is the only factor endowment variable affecting trade values statistically significantly. In fact, the first and third panels suggest that when the two countries are very distant in terms of capital endowments, they trade more in poultry products with lower prices. However, controlling for country-time effects makes trade variables very sensitive to the differences in factor endowments with large but statistically insignificant coefficients. Depreciation of domestic currency against the trade partner's currency reduces the traded quantity, but it also decreases the unit value of the imported product. When an NMS accesses the EU, its imports from all trade partners become cheaper, according to the results of the first specification. Moreover, when both partners become EU members and their trade becomes part of intra-EU trade, the traded unit value increases, which might reflect the quality improvement. Controlling for zero trade flows in the Poisson regression, when both partners are EU members, they experience higher trade integration.

\section{Ad Valorem Equivalents (AVEs) of NTMs}

In the previous section, the impact of NTMs on bilateral trade flows to single EU member states was presented. Quality standards and regulations embodied within the NTMs can have a diverse impact on bilateral trade flows depending on the type of product and the exporting partner. When the production process and quality of standards are at a similar level between the two trade partners, the impact of NTMs might promote trade. This happens because of the trade diversion from countries that produce the product with lower standards (compared to the ones in the imposing country) to countries with equal or higher standards than those existing in the imposing country. Thus, the trade implication of NTMs can be analyzed more accurately when exporters and products are differentiated rather than pooling them in one econometrics sample. 
Additionally, the impact of NTMs on trade values might stem from different channels of quantity and quality. When a trade-restrictive NTM is aimed at quality improvement of the imported product, this is likely reflected in a higher price of imports. However, depending on the preferences of consumers for higher or lower quality, trade values might go in opposite directions. On the other hand, the imposed NTM might have no impact on the quality but influence the price due to higher trade costs or trade facilitation. Depending on the demand elasticity of the product, this can lead to higher trade values even if the demanded quantity becomes lower.

Applying a two-stage framework first proposed by Looi Kee, Nicita, and Olarreaga (2009), further developed by Beghin, Disdier, and Marette (2015) allowing for positive externalities of NTMs, and Ghodsi, Gruebler, and Stehrer (2016a) additionally allowing to differentiate the impact by importers and the intensity of NTM types, we estimate the bilateral AVE for each type of NTM. In the first stage, bilateral import demand elasticities at the 6-digit level of the HS are estimated, which are differentiated by the country of origin of the imported product ${ }^{7}$. These elasticities are borrowed from an earlier study by Ghodsi et al. (2016b). In the second stage, using the number of each type of NTMs in force and interacting them with country-pair dummies, the impact of NTMs on the traded quantities is estimated as follows:

$$
\begin{aligned}
& \ln \left(q_{i j h t+1}\right)=\alpha_{0}+\alpha_{T} \ln \left(1+T_{i j h t}\right)+\sum_{n=1}^{N} \alpha_{n} \omega_{i j h} N T M_{n i j h t}+\beta_{1} G_{i j t}+\beta_{2} E U_{i t}+ \\
& +\omega_{i j h}+\omega_{t}+\mu_{i j h t}, \\
& n \in\{T B T, S P S, T B T \text { STC, SPS STC, SSG, ADP }\},
\end{aligned}
$$

where the traded quantity $q_{i j h t+1}$ is estimated over independent variables by each 6 -digit product $h$ in a panel data covering all countries in the world ${ }^{8}$. Compared

7 For a detailed methodological framework on bilateral elasticities, refer to Ghodsi, Gruebler, and Stehrer (2016b) and Ghodsi and Stehrer (2017).

8 The reason for separating the product sample is to allow for faster estimations. The reason for having all countries in the world as importers is to differentiate the imposed NTMs by the EU from an average NTM's impact of a benchmark importer. 
to equation (1), here NTMs are not in logarithm in order to calculate the AVEs from the coefficients as explained below. Also, each NTM is interacted with a country-pair dummy $\left(\omega_{i j h}\right)$. Since NTMs imposed by the EU are the same across all EU members, there is one distinct dummy for all EU members as importers. Moreover, the number of NTMs for intra-EU trade is set at zero. Hence, coefficient $\alpha_{n} \omega_{i j h}$ would give the distinct impact of the NTM on that bilateral trade flow to all EU members. However, due to differences in the elasticities across importers, the AVE of EU member states will differ. Because inclusion of all interactions with six types of NTMs exhausts the degrees of freedom, six estimations are run separately for each NTM-dummy interaction including other types of NTMs as control variables. The rest of the variables are similar to equation $(1)^{9}$. Inclusion of numerous interaction variables with many zero values does not allow Poisson regression to converge, thus, panel FE estimation is used.

Finally, having estimated the bilateral quantity impacts $\left(\alpha_{n} \omega_{i j h}\right)$ and the bilateral import demand elasticities $\left(\varepsilon_{i j h}\right)$ at hand, the bilateral AVE for each type of NTM is calculated as follows:

ave $_{n i j h}=\frac{1}{\varepsilon_{i j h}} \frac{\partial \ln \left(q_{i j h}\right)}{\partial N T M_{i j h}}=\frac{e^{\alpha_{n} \omega_{i j h}}-1}{\varepsilon_{i j h}}$.

\subsection{Results}

Table 2 presents the bilateral AVEs of NTMs imposed by the EU from 1996 to 2014 averaged over all EU-28 members. The results suggest that SPS measures imposed by the EU have had a statistically significantly positive effect on 799 product trade flows, whereas 703 flows have been affected negatively ${ }^{10}$. However, transposing the quantity effect into the AVEs using elasticities - of which some are positive - suggests that 788 of those SPS measures are characterized by

9 It is important to note that country-year FE is removed in the specification that was collinear with NTM-dummy interactions.

10 The detailed estimations are available from the authors upon request. 
positive AVEs showing restrictiveness. The simple average (s.a.) of coefficients is negative, indicating that an additional SPS measure imposed by the EU reduces trade quantity to a single member state by 0.15 percent on average. Averaging across all EU-28 member states using import weights results in an average positive effect, indicating a 1.8 percent increase in bilateral trade flows to a single EU member after imposition of a new SPS measure. This result is in line with the ones discussed earlier. In fact, major trade partners' exports of poultry to the EU have benefited from the SPS measures imposed by the EU while others' exports to the EU were restricted by these measures. However, AVEs for SPS STCs show high restrictiveness for major trade partners. Trade-weighted average AVEs for the STCs raised against the EU poultry SPS measures are equivalent to a 27.74 percent tariff. This might indicate why those trade partners raised STCs against SPS measures.

The impact of TBTs on bilateral imports of poultry to the EU is slightly different. Both simple and weighted average AVEs of these measures show trade restrictiveness. About 60 percent of significant coefficients of TBTs are negative. Import weighted average of AVEs for technical regulations imposed by the EU on bilateral product flows is equivalent to about 6 percent, while this jumps to around 100 percent for the STCs raised against the TBTs. In fact, two-thirds of statistically significant coefficients of TBT STCs indicate reductions in trade quantities.

Only three bilateral flows to the EU are affected by the imposed ADP measures. These are the imports from Taiwan to France, Ireland, and Poland. While the AVE of ADP measures imposed by Ireland is around 100 percent, this indicator for the other two importers is around 1 percent in average. This surprising result comes from the AVE of SSGs showing a negative sign using both types of averages. In the previous section, the average impact of SSGs imposed by the EU on the trade quantity was statistically insignificant. This is also reflected in the equal number of positive and negative AVEs of these measures. 
Table 2: Bilateral AVEs of NTMs Imposed by the EU during 1996-2014 (EU-28 average)

\begin{tabular}{|c|c|c|c|c|c|c|}
\hline EU-28 & SPS & SPS STC & TBT & TBT STC & ADP & SSG \\
\hline AVE (s.a.) & $0.39 \%$ & $-0.05 \%$ & $0.19 \%$ & $0.43 \%$ & $0.04 \%$ & $-0.40 \%$ \\
\hline$\alpha_{n}$ (s.a.) & -0.0015 & -0.009 & -0.013 & -0.026 & -0.003 & -0.007 \\
\hline AVE (w.a.) & $-10.63 \%$ & $27.74 \%$ & $6.00 \%$ & $99.67 \%$ & $99.87 \%$ & $-11.34 \%$ \\
\hline$\alpha_{n}$ (w.a.) & 0.018 & -0.073 & -0.079 & 0.672 & -6.608 & -0.088 \\
\hline Positive $\alpha_{n}$ & 799 & 113 & 412 & 45 & 0 & 372 \\
\hline Negative $\alpha_{n}$ & 703 & 130 & 600 & 91 & 3 & 273 \\
\hline Positive AVE & 788 & 98 & 572 & 100 & 3 & 322 \\
\hline Negative AVE & 714 & 145 & 440 & 36 & 0 & 323 \\
\hline
\end{tabular}

Notes: Only trade flows with statistically significant estimates at the $10 \%$ level are used. s.a. refers to simple averages, w.a. refers to import-weighted averages.

Source: Authors' estimations.

The estimations showing AVEs for each trade partner and each EU member as an importer indicate that even for some of the EU members as exporters, the AVEs are positive showing restrictiveness ${ }^{11}$.

\section{Quality Impact of EU Measures}

\subsection{Methodology}

In the previous section, EU measures were found to be diversely affecting the poultry import quantities and prices. Usually, price of imports or traded unit values are considered as proxies for the quality of products. Products from developed countries that have higher quality are associated with higher unit values of trade. An NTM that is imposed against the import of a product can increase its price. However, it should not necessarily mean that the quality of the product is also increased. When the quality of the product is not affected by an NTM, the price can increase if the NTM induces a burden to the exporter as either a fixed or an ad valorem cost of exporting. In contrast, an NTM that is aimed at improving the market efficiency might decrease the costs of marketing of the product, which

11 The detailed estimations are available from the authors upon request. 
can be reflected as a lower price but a similar quality. Therefore, it is difficult to distinguish between the quality and the quality-adjusted price.

Feenstra and Romalis (2014) propose a theoretical framework to disentangle trade values into a quantity, quality, and quality-adjusted price component. In their framework, both supply-side characteristics to produce higher quality based on higher productivity of firms, and consumer-driven characteristics for higher preferences for quality are implemented. Quality of the traded product is affected by both sides of trade, that is, by net costs associated with production of the product. Their final database on SITC Rev. 2 classification gives balanced bilateral trade values, quantity, unit values, quality, quality-adjusted price, and qualityadjusted quantity. Using these data allows us to track the impact of NTMs on the quality and net price of quality of the traded products.

The specification is changed here to a sample of EU-28 bilateral imports from all trade partners as follows:

$$
\begin{aligned}
& \ln \left(\rho_{i j h t+1}\right)=\alpha_{0}+\alpha_{T} \ln \left(1+T_{i j h t}\right)+\sum_{n=1}^{N} \alpha_{n} \omega_{i j h} \ln \left(1+N T M_{n i j h t}\right)+\beta_{1} G_{i j t}+\beta_{2} E U_{i t}+ \\
& +\omega_{i j h}+\omega_{t}+\mu_{i j h t}, \\
& n \in\{T B T, \text { SPS, TBT STC, SPS STC }\} .
\end{aligned}
$$

In the results presented below, the dependent variable $\rho$ is either the quality of imported product or the unit value. The information on these variables is from Feenstra and Romalis (2014), covering the sector 0114 of SITC Rev. 2. Here instead of number of NTMs at levels, their logarithmic form is used to capture the elasticity impact. Since SSG and ADP measures are not quality-relevant regulations, these are included in the regressions as control variables. Other variables and econometric specifications remain unchanged. This specification including exporter-NTM interaction hints towards the diverse quality impact of EU regulations. In fact, for some countries that have already been producing with an equivalent quality to the EU standards, the imposed NTM might not have any significant impact. Based on the theoretical framework, quality levels of products 
are structured relative to a benchmark country. Therefore, when a product's quality from a specific exporter does not change while other exporters improve the quality of that product, the relative position of the focal exporter's product quality is degraded. Thus, for each type of NTM, there will be one coefficient for an exporting country to analyze the impact. Both OLS and Poisson techniques with country-pair $\left(\omega_{i j h}\right)$ and time $\left(\omega_{t}\right)$ fixed effects are used for this analysis. Both techniques yield similar results.

\subsection{Results}

Table 3 presents the impact of the NTMs imposed by the EU on the quality (Q) and price $(\mathrm{P})$ of the imported poultry from all exporting partners. These are in fact coefficients of each NTM $n$ imposed by the EU against partner $j\left(\alpha_{n} \omega_{i j h}\right)$ that are statistically significant at the 10 percent level. The results suggest that both SPS and TBT measures imposed by the EU influence the quality of imports positively for many exporters. The results can be interpreted in the following example. A 1 percent increase in the number of SPS measures imposed by the EU would increase the total unit value of poultry from the United Arab Emirates (ARE) by 350 percent, while around 48 percent of this increase (167 percent compared to 350 percent) is due to the quality improvement effect. In fact, a 1 percent increase in the number of EU SPS measures will increase the quality and the quality-adjusted price of imports from ARE by 167.4 percent and 183 percent, respectively. While this impact is very large for ARE, for many other exporters this impact is close to zero.

An interesting finding refers to the impact of SPS measures on the imports from the US. The results suggest that since $1997^{12}$, a 1 percent additional SPS measure imposed by the EU would decrease the quality of imports from the US by 0.165 percent. While the price impact is about -0.161 percent, the EU regulations

12 As explained before, the forward value of the dependent variable is used to reduce the simultaneity bias, which results in a one-year reduction of the sample. Moreover, quality data is available up to 2011 . Therefore, the period of this analysis is 1997-2011. 
had a small positive impact on the quality-adjusted price of 0.004 percent. In fact, the EU regulations increased the costs of the imports from the US while degrading their quality. However, the SPS STCs raised by the US had a small positive impact on the quality and price of the imports. The EU regulations against the use of antimicrobial treatments (AMTs) were in place to prohibit misuse of these chemicals that were used to mitigate the low hygienic quality of the products through shipment, as reported in the notification. Complying with these regulations by the US exporters shows that the quality of their products has slightly reduced without these substances. TBTs have increased the quality of the products from the US while reducing their prices. This might refer to technical regulations that improve the market efficiencies by reducing the cost and improving the qualitative characteristics of products, especially those that are produced in similar standard settings. Therefore, it is important to note that these results are not based on any qualitative testing of the products but on economic quantification of quality and prices.

Quality and price of the two major exporters of poultry to the EU, namely Brazil and Argentina, are both affected negatively by NTMs. In contrast, NTMs imposed by the EU enhanced both quality and price of poultry from Thailand and China, two other major exporters. While quality and price of imports from Israel are not affected by these NTMs, price of poultry from Chile, another major exporter, is increased by SPS and SSG measures. Furthermore, quality and price of poultry from Canada are affected negatively by SPS measures. Again, negative impact of NTMs on the quality of imports from EU member states indicates a negative role of NTMs imposed by the NMSs before accession to the EU. This impact neutralized after harmonization with EU standards. 
Table 3: Bilateral Quality and Price Impact of NTMs Imposed by the EU during 1996-2011

\begin{tabular}{|c|c|c|c|c|c|c|c|c|}
\hline NTM & \multicolumn{2}{|c|}{ SPS } & \multicolumn{2}{|c|}{ TBT } & \multicolumn{2}{|c|}{ TBT STC } & \multicolumn{2}{|c|}{ SPS STC } \\
\hline Exporter & $Q$ & $P$ & $Q$ & $P$ & $Q$ & $P$ & $Q$ & $P$ \\
\hline ARE & $167.4 \%$ & $350.4 \%$ & $26.6 \%$ & $51.5 \%$ & & & & \\
\hline ARG & $-9.6 \%$ & $-11.4 \%$ & & & & & $-9.3 \%$ & \\
\hline AUS & $75.3 \%$ & $187.5 \%$ & $65.9 \%$ & $166.9 \%$ & & & & \\
\hline AUT & $-0.1 \%$ & $-0.2 \%$ & & & & & & \\
\hline BEL & $0.0 \%$ & $0.1 \%$ & $0.0 \%$ & $0.0 \%$ & & & & \\
\hline BEN & $10.4 \%$ & $32.9 \%$ & $13.3 \%$ & $33.9 \%$ & & & & \\
\hline BGR & & & $-3.5 \%$ & & & & & \\
\hline BRA & $-0.3 \%$ & $-0.3 \%$ & $-2.6 \%$ & & $-12.3 \%$ & $-20.7 \%$ & & \\
\hline CAN & $-4.4 \%$ & $-6.3 \%$ & & & & & & \\
\hline $\mathrm{CHE}$ & $5.1 \%$ & $16.7 \%$ & $6.7 \%$ & $20.0 \%$ & & & $-13.0 \%$ & $-46.7 \%$ \\
\hline CHL & & $11.0 \%$ & & & & & & \\
\hline $\mathrm{CHN}$ & $4.1 \%$ & $6.0 \%$ & $6.7 \%$ & & & & & \\
\hline CYP & $-0.7 \%$ & $-0.9 \%$ & & & & & & \\
\hline $\mathrm{CZE}$ & $5.2 \%$ & $17.2 \%$ & $6.6 \%$ & $20.4 \%$ & & & & \\
\hline $\mathrm{DEU}$ & $0.0 \%$ & $0.0 \%$ & $0.0 \%$ & $0.0 \%$ & & & & \\
\hline DNK & $0.0 \%$ & $0.1 \%$ & $0.0 \%$ & $0.0 \%$ & & & & \\
\hline ESP & $0.0 \%$ & $0.0 \%$ & & $0.0 \%$ & & & & \\
\hline EST & & $1.1 \%$ & & $1.1 \%$ & & & & \\
\hline FIN & $0.0 \%$ & $0.1 \%$ & & & & & & \\
\hline FRA & $0.0 \%$ & $0.1 \%$ & $0.0 \%$ & $0.0 \%$ & & & & \\
\hline GBR & $0.1 \%$ & $0.2 \%$ & & $0.0 \%$ & & & & \\
\hline $\mathrm{GEO}$ & $15.4 \%$ & $31.7 \%$ & $351.3 \%$ & $884.5 \%$ & & & & \\
\hline GRC & $-0.8 \%$ & $-1.7 \%$ & & & & & & \\
\hline HRV & $4.0 \%$ & & & $-17.7 \%$ & & & & \\
\hline HUN & $0.2 \%$ & $0.3 \%$ & $-2.4 \%$ & $0.2 \%$ & & & & \\
\hline IRL & $0.0 \%$ & $0.0 \%$ & $0.0 \%$ & $0.0 \%$ & & & & \\
\hline ITA & $-0.1 \%$ & $-0.1 \%$ & $0.0 \%$ & $0.0 \%$ & & & & \\
\hline KWT & $18.8 \%$ & $24.2 \%$ & & & & & & \\
\hline LTU & $-7.5 \%$ & $-32.5 \%$ & $-14.9 \%$ & $-55.3 \%$ & & & & \\
\hline NLD & $0.0 \%$ & $0.0 \%$ & $0.0 \%$ & $0.0 \%$ & & & & \\
\hline NOR & $54.8 \%$ & $140.8 \%$ & $24.0 \%$ & $57.5 \%$ & & & & \\
\hline POL & $4.8 \%$ & $7.8 \%$ & $3.8 \%$ & $0.0 \%$ & & & & \\
\hline PRT & $0.0 \%$ & $0.0 \%$ & & & & & & \\
\hline $\mathrm{ROM}$ & & $8.6 \%$ & & & & & & \\
\hline SVK & $0.0 \%$ & $-0.1 \%$ & $-0.1 \%$ & $-0.3 \%$ & & & & \\
\hline SVN & $-0.1 \%$ & $-0.3 \%$ & & & & & & \\
\hline SWE & $0.1 \%$ & $0.1 \%$ & & & & & & \\
\hline THA & $6.7 \%$ & $9.9 \%$ & $6.9 \%$ & $7.1 \%$ & & & & \\
\hline TUN & $6.6 \%$ & $10.9 \%$ & $5.9 \%$ & $8.8 \%$ & & & & \\
\hline TUR & $7.0 \%$ & $16.8 \%$ & & & & & & \\
\hline URY & $-4.4 \%$ & $-15.4 \%$ & $-4.7 \%$ & $-21.5 \%$ & & & & \\
\hline USA & $-0.2 \%$ & $-0.2 \%$ & $2.2 \%$ & $-5.6 \%$ & & $-12.2 \%$ & $0.0 \%$ & $0.0 \%$ \\
\hline $\mathrm{ZAF}$ & $-19.5 \%$ & $-40.4 \%$ & $-80.2 \%$ & $-143.2 \%$ & & & & \\
\hline ZWE & $10.2 \%$ & $25.4 \%$ & $4.0 \%$ & $8.4 \%$ & & & & \\
\hline
\end{tabular}

Note: Only trade flows with statistically significant estimates at the $10 \%$ level are used.

Source: Authors' estimations. 


\section{Summary and Concluding Remarks}

The legal system in the EU is structured in a way that obliges producers to prove that their products do not harm the consumer. In contrast, WTO regulations similar to the legal system in the USA stipulate that consumers have to prove that a product harms them. Therefore, unless there is scientific evidence proving the harms of a traded product in the focus of an NTM, it will be very hard for the DSB to justify such an EU regulation. Some dispute settlement cases have prescribed penalties and remedies against EU regulations. Cases of prohibition of imports of meat produced with hormones and biotech feed such as GMOs have led to the imposition of large penalties against the European Community as it was unable to provide any scientific evidence of the products' harmfulness. Another ongoing dispute concerns the chicken or poultry washed with certain AMTs, which has recently been in the media spotlight. There is no evidence to justify an EU regulation prohibiting such imports but the consumers' community is concerned about the availability of such products in the EU market.

In this study, we analyze the imports of poultry to the EU with a special focus on the role of NTMs imposed by the EU. The small share of extra-EU poultry imports and the downward trend of this share in the past several years might indicate that the EU poultry market is well protected. While tariffs have been gradually decreasing over the years, an increasing number of NTMs have come into place. In a gravity framework, poultry imports (at the 6-digit level of the Harmonized System) to the 28 EU members during the 1996-2014 period were analyzed. A statistically significant negative impact of tariffs and technical barriers to trade on the imports of poultry was found. However, in two specifications controlling for multilateral resistances and zero trade flows, the results indicated that sanitary and phytosanitary (SPS) measures imposed by the EU increase the trade values and quantities significantly. Moreover, STCs raised against TBTs and SPS measures were found to increase the unit values of imports. 
Exporting countries are heterogeneous in many aspects, including the level of standards at which they are producing. Exports of a country producing poultry at a lower level of quality than the EU standards might be affected negatively. In contrast, trade of a country that is producing with similar standards as the EU can benefit from the regulative trade policy measures imposed by the EU. Using a two-stage methodology, we calculated the bilateral AVEs for five types of NTMs imposed by the EU. The diverse impact of NTMs on different exporters resulted in various AVEs for NTMs. Some AVEs indicate trade promotion, such as negative AVEs for SPS measures for the USA and China. Moreover, the findings suggest that SPS measures maintained by the EU were in favor of major exporters of poultry to the EU, while other measures were generally restrictive.

The last part of the analysis was dedicated to the quality impact of NTMs on poultry imports to the EU. The diverse impacts of EU regulations on the quality of imports from different countries again show that the standards frameworks in exporting countries are very heterogeneous. The results suggest that SPS measures have influenced upgrading the quality of poultry imported from many countries, while degrading the quality and prices of imports from some major exporters. EU regulations prohibiting the use of AMTs suggested that these substances were used to mitigate the low hygienic quality of poultry. This means that not using them would lead to lower quality of the imported products, which could also be observed in the econometrics results. 


\section{Literature}

Anderson, J. E. (1979). A theoretical foundation for the gravity equation. The American Economic Review, 69(1), 106-116.

Anderson, J. E., \& van Wincoop, E. (2003). Gravity with gravitas: A solution to the border puzzle. The American Economic Review, 93(1), 170-192. doi: https:// doi.org/10.1257/000282803321455214

Arkolakis, C., Costinot, A., \& Rodríguez-Clare, A. (2012). New trade models, same old gains? The American Economic Review, 102(1), 94-130. doi: https://doi. org/10.1257/aer.102.1.94

Baldwin, R., \& Taglioni, D. (2007). Trade effects of the euro: A comparison of estimators. Journal of Economic Integration, 22(4), 780-818. doi: https://doi. org/10.11130/jei.2007.22.4.780

Baltagi, B. H., Egger, P., \& Pfaffermayr, M. (2003). A generalized design for bilateral trade flow models. Economics Letters, 80(3), 391-397. doi: https://doi. org/10.1016/S0165-1765(03)00115-0

Bao, X., \& Qiu, L. D. (2012). How do technical barriers to trade influence trade? Review of International Economics, 20(4), 691-706. doi: https://doi.org/10.1111/ j.1467-9396.2012.01047.x

Beghin, J. C., Disdier, A. C., \& Marette, S. (2015). Trade restrictiveness indices in the presence of externalities: An application to non-tariff measures. Canadian Journal of Economics/Revue canadienne d'économique, 48(4), 1513-1536. doi: https://doi.org/10.1111/caje.12157

Bingzhan, S. (2011). Extensive margin, quantity and price in China's export growth. China Economic Review, 22(2), 233-243. doi: https://doi.org/10.1016/j. chieco.2011.01.007

Bown, C. P., \& Hillman, J. A. (2016). Bird flu, the OIE, and national regulation: The WTO's India-agricultural products dispute. World Trade Review, 15(2), 235257. doi: https://doi.org/10.1017/S1474745615000701 
Bown, C. P., \& Hillman, J. A. (2017). Foot-and-mouth disease and Argentina's beef exports: The WTO's US-animals dispute. World Trade Review, 16(2), 253 277. doi: https://doi.org/10.1017/S1474745616000537

Dal Bianco, A., Boatto, V. L., Caracciolo, F., \& Santeramo, F. G. (2015). Tariffs and non-tariff frictions in the world wine trade. European Review of Agricultural Economics, 43(1), 31-57. doi: https://doi.org/10.1093/erae/jbv008

De Frahan, B. H., \& Vancauteren, M. (2006). Harmonisation of food regulations and trade in the single market: Evidence from disaggregated data. European Review of Agricultural Economics, 33(3), 337-360. doi: https://doi.org/10.1093/ eurrag/jbl015

Dhingra, S., Huang, H., Ottaviano, G., Pessoa, J. P., Sampson, T., \& Van Reenen, J. (2017). The costs and benefits of leaving the EU: Trade effects. Economic Policy, 32(92), 651-705. doi: https://doi.org/10.1093/epolic/eix015

Disdier, A. C., Fontagné, L., \& Cadot, O. (2015). North-south standards harmonization and international trade. The World Bank Economic Review, 29(2), 327-352. doi: https://doi.org/10.1093/wber/lht039

Disdier, A. C., Fontagné, L., \& Mimouni, M. (2008). The impact of regulations on agricultural trade: Evidence from the SPS and TBT agreements. American Journal of Agricultural Economics, 90(2), 336-350. doi: https://doi.org/10.1111/ j.1467-8276.2007.01127.x

Eaton, J., \& Kortum, S. (2002). Technology, geography, and trade. Econometrica, 70(5), 1741-1779. doi: https://doi.org/10.1111/1468-0262.00352

Feenstra, R. C., Inklaar, R., \& Timmer, M. P. (2015). The next generation of the Penn World Table. The American Economic Review, 105(10), 3150-3182. Retrieved from: http://www.ggdc.net/pwt. doi: https://doi.org/10.1257/aer.20130954

Feenstra, R. C., \& Romalis, J. (2014). International prices and endogenous quality. The Quarterly Journal of Economics, 129(2), 477-527. doi: https://doi. org/10.1093/qje/qju001 
Fontagné, L., Mimouni, M., \& Pasteels, J. M. (2005). Estimating the impact of environmental SPS and TBT on international trade. Integration and Trade Journal, 22(3), 7-37. Retrieved from: https://ssrn.com/abstract=1260862

Ghodsi, M., Gruebler, J., \& Stehrer, R. (2016a). Estimating importer-specific ad valorem equivalents of non-tariff measures, wiiw Working Paper No. 129. Vienna: The Vienna Institute for International Economic Studies.

Ghodsi, M., Gruebler, J., \& Stehrer, R. (2016b). Import demand elasticities revisited, wiiw Working Paper No. 132. Vienna: The Vienna Institute for International Economic Studies.

Ghodsi, M., Grübler, J., Reiter, O., \& Stehrer, R. (2016). The evolution of nontariff measures and their diverse effects on trade [Mimeo].

Ghodsi, M., \& Stehrer, R. (2017). NTMs in the presence of global value chains [Mimeo].

Head, K., \& Mayer, T. (2014). Gravity equations: Workhorse, toolkit, and cookbook. In G. Gopinath, E. Helpman, \& K. Rogoff (Eds.), Handbook of international economics (Vol. 4, pp. 131-195). doi: https://doi.org/10.1016/ B978-0-444-54314-1.00003-3

Helpman, E., Melitz, M., \& Rubinstein, Y. (2008). Estimating trade flows: Trading partners and trading volumes. The Quarterly Journal of Economics, 123(2), 441-487. doi: https://doi.org/10.1162/qjec.2008.123.2.441

Imbruno, M. (2016). China and WTO liberalization: Imports, tariffs and non-tariff barriers. China Economic Review, 38(C), 222-237. doi: https://doi. org/10.1016/j.chieco.2016.02.001

Jayasinghe, S., Beghin, J. C., \& Moschini, G. (2010). Determinants of world demand for US corn seeds: The role of trade costs. American Journal of Agricultural Economics, 92(4), 999-1010. doi: https://doi.org/10.1093/ajae/aaq056 
Larch, M., Wanner, J., Yotov, Y. V., \& Zylkin, T. (2018). Currency unions and trade: A PPML re-assessment with high-dimensional fixed effects. Oxford Bulletin of Economics and Statistics, 81(3), 487-510. doi: https://doi.org/10.1111/ obes. 12283

Looi Kee, H., Nicita, A., \& Olarreaga, M. (2009). Estimating trade restrictiveness indices. The Economic Journal, 119(534), 172-199. doi: https://doi.org/10.1111/ j.1468-0297.2008.02209.x

Melitz, M. J. (2003). The impact of trade on intra-industry reallocations and aggregate industry productivity. Econometrica, 71(6), 1695-1725. doi: https:// doi.org/10.1111/1468-0262.00467

Melo, O., Engler, A., Nahuehual, L., Cofre, G., \& Barrena, J. (2014). Do sanitary, phytosanitary, and quality-related standards affect international trade? Evidence from Chilean fruit exports. World Development, 54, 350-359. doi: https://doi. org/10.1016/j.worlddev.2013.10.005

Otsuki, T., Wilson, J. S., \& Sewadeh, M. (2001). What price precaution? European harmonisation of aflatoxin regulations and African groundnut exports. European Review of Agricultural Economics, 28(3), 263-284. doi: https://doi. org/10.1093/erae/28.3.263

Peterson, E., Grant, J., Roberts, D., \& Karov, V. (2013). Evaluating the trade restrictiveness of phytosanitary measures on US fresh fruit and vegetable imports. American Journal of Agricultural Economics, 95(4), 842-858. doi: https://doi. org/10.1093/ajae/aat015

Silva, J. S., \& Tenreyro, S. (2006). The log of gravity. The Review of Economics and Statistics, 88(4), 641-658. doi: https://doi.org/10.1162/rest.88.4.641

Tinbergen, J. (1962). Shaping the world economy: Suggestions for an international economic policy. New York, NY: Twentieth Century Fund.

UN Comtrade. (n.d.). United Nations commodity trade statistics database. Retrieved from: https://comtrade.un.org/db/default.aspx 
Winchester, N., Rau, M. L., Goetz, C., Larue, B., Otsuki, T., Shutes, K., ... Nunes de Faria, R. (2012). The impact of regulatory heterogeneity on agri-food trade. The World Economy, 35(8), 973-993. doi: https://doi.org/10.1111/j.14679701.2012.01457.x

Yotov, Y. V., Piermartini, R., Monteiro, J. A., \& Larch, M. (2016). An advanced guide to trade policy analysis: The structural gravity model. Geneva: World Trade Organization. doi: https://doi.org/10.30875/abc0167e-en 


\section{List of abbreviations:}

\begin{tabular}{l|l}
\hline Abbreviation & Definition \\
\hline AMT & Antimicrobial treatments \\
\hline ARG & Argentina \\
\hline AVE & Ad valorem equivalent \\
\hline BRA & Brazil \\
\hline CHL & Chile \\
\hline CHN & China \\
\hline DSB & Dispute Settlement Body \\
\hline EU & European Union \\
\hline GMO & Genetically modified organisms \\
\hline ISR & Israel \\
\hline NMS & New member states \\
\hline NTM & Non-tariff measures \\
\hline PRT & Pathogen reduction treatments \\
\hline RoW & Rest of the world \\
\hline SPS & Sanitary and phytosanitary measures \\
\hline SSG & Special safeguards \\
\hline STC & Specific trade concern \\
\hline TBT & Technical barriers to trade \\
\hline THA & Thailand \\
\hline TWA & Trade-weighted average \\
\hline UKR & Ukraine \\
\hline USA & United States of America \\
\hline WTO & World Trade Organization \\
\hline
\end{tabular}

